\title{
Utilising virtual reality in alcohol studies - a systematic review
}

James Durl ${ }^{a, b}$, Timo Dietrich ${ }^{a, b, c, e}$, Bo Pang a , Leigh-Ellen Potter ${ }^{b}$ and Lewis Carter ${ }^{b}$

a Social Marketing @ Griffith, Griffith University, Nathan, Queensland, Australia

${ }^{b}$ Department of Marketing, Griffith University, Nathan, Queensland, Australia

${ }^{c}$ Griffith Menzies Health Institute Griffith University, Southport, Queensland, Australia

d School of Information and Communication Technology, Griffith University, Nathan, Queensland, Australia

e Faculty of Medicine and Biomedical Sciences, Centre for Youth Substance Abuse, University of Queensland, St Lucia, Australia

\section{Abstract}

Background: The resurgence of VR in recent years has been exciting for health educators and researchers, yet little is known about VR's effectiveness. This systematic literature review aims to provide an overview of the prevalence of VR in alcohol studies and assess its effectiveness.

Methods: Peer reviewed articles were systematically searched from online databases including PubMed, ProQuest, Web of Science, Science Direct, Emerald, OVID, Taylor \& Francis, and EBSCO. Grey literature and conference papers were excluded. Studies that passed the inclusion criteria were qualitatively assessed.

Findings: Of the 1739 studies retrieved, eight studies met the inclusion criteria. Three main applications of VR were found; 1) Cue-exposure therapy, 2) Driving simulators for examining relationships between alcohol and neurological activity, and 3) Training of healthcare professionals. Only one study focused on adolescents, and only one study reported longitudinal outcomes.

Conclusion: VR remains underutilised in alcohol studies. VR was indicated positive results across the three contexts, however longitudinal evidence remains limited and therefore restricts the generalisability of findings. More long-term empirical research is warranted.

\section{Keywords}

Virtual reality, systematic review, alcohol studies, prevention, intervention

\section{Corresponding author:}

James Durl, Griffith University Business School, 170 Kessels Road, Nathan Campus, Nathan, Queensland, 4111, Australia

Email: james.durl@griffithuni.edu.au 


\section{Background}

With the value of global alcohol sales at approximately $\$ 1$ trillion U.S. dollars annually (Jernigan and Babor, 2015), alcohol remains a significant source of harm across the world. Alcohol consumption is associated with over 200 health conditions (WHO, 2014) and accounts for approximately $5.1 \%$ of the global burden of disease. Each year, around 3.3 million deaths worldwide, $5.9 \%$ of all deaths are attributed to alcohol (World Health Organisation, 2014). Alcohol-related problems such as alcohol fuelled violence (Scott, 2015; Bavas, 2015) and drink driving behaviour (Australian Institute of Criminology, 2014; Mayor, 2011) often feature in the media and are the focus of government initiatives including law and policy changes and Public Service Announcement (PSA) campaigns.

Even though interventions that utilised traditional communication methods have managed to reduce alcohol consumption (Kubacki et al., 2015), there has been limited technological innovation in this area. An example of innovation in alcohol studies has been observed in the application of gamification. Gamification is the use of game design elements for out of game environment purposes (Deterding et al., 2011), a principle that can be applied in online games and practical activities to engage and influence a target group. Johnson et al. (2016) found that gamification supports interventions concerning young participants' wellbeing and has been successfully used to motivate and track individual health and well-being behaviour. For example, gamification has been successfully used to deliver alcohol education to 14-16-year-old adolescents in Australia, delivering initial successes by increasing alcohol knowledge and changing attitudes for the better (Rundle-Thiele et al., 2015). A novel but yet underexplored gamification technology in alcohol studies is Virtual Reality (VR), which has demonstrated increased engagement and reactivity towards alcohol cues using virtual environments (Bordnick et al., 2008).

VR refers to computer-generated simulations or environments (Biocca and Levy, 1995) that a person experiences through a technological application (Krueger, 1991). The aim of VR is to simulate sensory information from the real world, such as audio, tactile and visual input, and deliver it to a person through artificial means (Boas, 2013). VR technology has become popularised in recent years, due in no small part to the rising number of Head Mounted Displays (HMDs) available to consumers (Olszewski, 2016). HMDs are devices often resembling visors or helmets that a person wears to immerse themselves in virtual environments while simultaneously blocking out visual stimuli of actual reality (Laramee and Ware, 2002). Immersive methods also including CAVE rooms or BOOM VR stands (Cruz-Neira, Sandin, and DeFanti, 1993) are preferable to low level immersive VR delivery methods such as interactive computer programmes. This is demonstrated by the considerable attention drawn to VR through HMDs in areas such as entertainment, largely due to their size, accessibility and often portable nature (Olszewski, 2016).

Zyda (2005) stated that for VR research to stay relevant it must be performed in the sphere of game development. Within this sphere, serious games have indicated improved teaching outcomes. While gamification refers to introducing game elements for out of game environment purposes (Deterding et al., 2011), serious games are entire games designed to relate educational messages and encourage behaviour change (Johnson et al., 2016). Bakhuys et al. (2015) demonstrated that serious games produced more positive learning outcomes compared to classroom instructions along self-reported assessments. Furthermore, Sárkány and colleagues (2015) surmise that not only can serious games be considered as groundwork for improving mental health in conditions such as dementia, but also that VR can be an 
effective mode of delivering such serious games. In addition to serious gaming and gamification, developments in VR span many contexts, including the environmental and marine sciences (Kim et al., 2014), sports training (An-Long, 2013) and medical science and training (Robison et al., 2011; Kuo et al., 2001).

However, there is limited research in the context of VR's application in alcohol studies. Therefore, a systematic investigation is warranted to establish the current evidence base of application and effectiveness of VR in alcohol studies, and provide direction for future research. To the best of the authors' knowledge, there is no existing review that solely investigates the application of VR in alcohol studies. This systematic literature review has two objectives. First, this study will determine the prevalence of VR components in alcohol studies. Second, the review aims to assess the effectiveness of VR components by comparing the outcomes of identified studies.

\section{Methodology}

This systematic literature review closely followed PRISMA reporting guidelines, as outlined by Liberati et al. (2009) and Moher et al. (2009) (see also http://www.prismastatement.org/Default.aspx.), with the aim to identify studies relating VR to alcohol. To do this, a PRISMA checklist was used to determine which criteria applied to this study and how accurately relevant criteria were applied. Eight online databases (PubMed, ProQuest, Web of Science, Science Direct, Emerald, OVID, Taylor \& Francis, EBSCO) were searched to identify relevant studies. Truncations were used to search multiple databases. For example, a question mark was used to replace the letter " $s$ " in "randomi?ed controlled trial" to pick up both American (Randomized) and British (Randomised) English spelling. The following search terms were used to find articles; "virtual reality" AND intervention OR "randomi?ed controlled trial" OR evaluation* OR trial* OR campaign* OR programme* OR study OR studies AND Health. The search yielded 1739 articles. 635 duplicates were removed, yielding 1104 articles for review (see flowchart in Figure 1 for paper selection process). The grey literature and conference papers were omitted from the search.

Exclusion criteria were then applied to sort all non-English, non-journal articles, formative/review papers, and other irrelevant studies (e.g., stroke rehabilitation studies utilising VR), leaving 405 potential studies. The remaining papers were screened based on their titles and abstracts, which resulted in five relevant studies that applied VR in an alcohol context. Backward and forward searches were performed on these studies, searching reference lists and other work by the authors of these papers. The authors also screened previously identified formative $(n=142)$ and review (e.g. systematic review papers $n=214$ ) articles, yielding a further three studies. The searches were conducted across all years, however all studies identified for this review were published after 2000. A total of eight studies were used for the analyses reported on in this review.

\section{FIGURE 1 TO BE INSERTED HERE}

One author performed data extraction for each study regarding classifications of the studies; outcomes identified; and design approach. Data recorded was tabulated in an Excel spreadsheet and reviewed by another author to check for accuracy of summaries and consensus on inferences made from studies. Analyses made regarding the eight studies were checked by the authors in order to ensure accuracy of the inferences and conclusions made. 
All eight identified studies from the systematic literature review were qualitatively assessed with details regarding the author information, year of publication, country of origin, target audience, sample size, objectives, methodology, theory, description, study design, results (outcomes), and the studies limitations (see Table 1 for more details).

\section{Findings}

All eight studies used VR and were executed in developed countries, with the majority in the USA $(N=6)$. The remaining studies were conducted in Canada $(\mathrm{N}=1)$ and South Korea $(\mathrm{N}=1)$. Three studies utilised HMDs for VR delivery (Bordnick et al., 2008; Hadley et al., 2014; Traylor et al., 2011) while the remaining five studies used interactive computer programmes. Five of the studies were cross-sectional, two followed a pre- and post- design (Hadley et al., 2014; Lee et al., 2007) and one study was longitudinal (Fleming et al., 2009). Seven of the identified studies targeted adults, with the remaining one study targeting young peopl (Hadley et al., 2014). Three different areas of VR application in alcohol emerged from the analysis. First, cueexposure therapy studies (CET) which elicit craving responses in study participants (Bordnick et al., 2008; Hadley et al., 2014; Lee et al., 2007; Traylor et al., 2011). Second, studies utilised driving simulations, in which relationships between alcohol consumption and neurological activity were examined (Arnedt et al., 2011; Meda et al., 2009; Rzepecki-Smith et al., 2009). The third area that was identified focused on training healthcare professionals (Fleming et al., 2009). A summary of all studies is presented in Table 1.

\section{TABLE 1 TO BE INSERTED ABOUT HERE}

The rationales behind each study varied substantially, mainly due to the different contextual applications. Of the eight identified studies, only one used VR for training purposes which was targeted at healthcare professionals to help with referral and treatment of people with alcohol related problems (Fleming et al., 2009). Three studies tested cross-cue reactivity amongst participants and determined the effect of cues on alcohol cravings and urges (Hadley et al., 2014; Lee et al., 2007; Traylor et al., 2011). The term 'cross-cue reactivity' is concerned with the observable reactions of individuals when exposed to cues (e.g., alcohol and/or tobacco) representing co-occurring behaviours (Cooney et al., 2007; Traylor et al., 2011). Bordnick et al. (2008) focused strictly on alcohol cue effects and their impact on cravings and urges rather than co-occurring behaviours. The remaining three studies (Arnedt et al., 2001; Meda et al., 2009; Rzepecki-Smith et al., 2009) sought to understand specific neurological activities with varying levels of Blood Alcohol Concentration, particularly with regards to detriments to decision making while driving a motor vehicle under the influence of alcohol.

While the specific objectives of the reviewed studies varied, they all attempted to examine VR's efficacy in engaging with participants in alcohol research contexts (see Table 2 ). Varying levels of success were reported by the studies' authors, with each of the studies utilising CET reporting successful cue-reactivity with participants, as well as noteworthy findings stemming from the alcohol studies surrounding driving behaviours. Long-term results were seen in Fleming et al. (2009), in which the improvements in knowledge gained by healthcare professionals from an interactive computer programme were maintained at six month follow-up. The findings of each study are discussed in more detail in the next section. 


\section{Discussion}

The objectives of this systematic literature review were to determine the prevalence of VR within alcohol studies, and to compare the effectiveness of the identified studies. The following discussion relates to the contexts identified in the studies, the various outcomes presented by each study, and a comparison between prevention and intervention approaches.

\section{VR Context}

While the focus of most identified VR alcohol studies fell into one of three described areas (CET, driving simulations, and training), the context of each of these studies varied substantially. For instance, two of the three driving simulations were conducted with participants laying in $\mathrm{fMRI}$ machines while simultaneously exposed to screens displaying interactive computer programs (Meda et al., 2009; Rzepecki-Smith et al., 2009) to track neurological activity while under the influence of alcohol. Arnedt et al.'s (2001) driving simulation was conducted in a sleep laboratory in order to measure detriments to driving under varying levels of sleepiness and blood alcohol concentration. As such, the aims of each study were heterogeneous despite the fairly homogeneous areas of research identified. For VR and alcohol research, this indicates a field of research that has many different prospective research paths, as well as subsequently numerous research gaps to investigate.

A point of similarity connecting these eight studies was that all VR simulations lacked graphical fidelity regarding key aspects to realism, such as driving simulators without the presence of other cars and very basic graphics (Meda et al., 2009; Rzepecki-Smith et al., 2009), or party and office rooms that were very elementary with regards to their graphics (e.g. Bordnick et al., 2008; Traylor et al., 2011). The recent advancements in VR technology along with its mainstream application may require future studies to place greater emphasis on graphical quality to meet VR user expectations. One of the integral parts to designing immersive and engaging VR studies is presence, as this refers to a participant's perception of immersion and feelings of 'being there' (Slater et al., 2009). Spatial awareness and distance compression have been identified as barriers to full presence, as participants are often preoccupied with their physical location preventing them from feeling immersed in virtual environments (Blom and Beckhaus, 2013).

Despite these shortfalls, some of the CET studies (see for example Bordnick et al., 2008) were perceived as immersive experiences and participants were seen reaching for virtual objects. This could be attributed to the use of HMDs in the respective studies. This reinforces the idea that real-world environments can be convincingly simulated within VR, potentially mediated by the type of VR technology used. Notwithstanding the popularity of HMDs mentioned previously, only three of the studies in this review used HMDs to deliver their VR content to participants (Bordnick et al., 2008; Hadley et al., 2014; Traylor et al., 2011). Research indicates that realism, immersion and the convincing nature of virtual characters and environments can improve the teaching process and encourage students to strengthen their own levels of knowledge (Hanson and Shelton, 2008).

Taken together, the graphical quality displayed in the identified studies, the small number of studies that have applied VR in alcohol studies as well as the limited utilisation of HMDs warrants future research that enhances the realism of VR environments and simulation 
experiences and expands on the application of VR in different areas of alcohol research. Codesign may provide a particularly useful methodology (Dietrich et al., 2017; de Visser et al., 2015) to design more realistic and engaging VR experiences. Yet, only two studies reported any type of user involvement when designing their studies and VR content. Hadley et al. (2014) designed the VR scenario through an iterative process with a sample of the target population. Lee et al. (2007) asked participants for their alcohol beverage preferences for their CET study. This was aimed to induce stronger cue-reactivity by displaying participant's preferred alcoholic beverages. However, other study components such as environmental cues and story elements were expert-driven and designed without user-involvement. Moving beyond expert-driven design approaches and involving target audiences will allow researchers and health educators to design more engaging VR content.

\section{VR Outcomes}

The identified studies demonstrated a focus on specific intervention settings, i.e. alcohol dependent or problem drinkers as subjects. Furthermore, the studies were characterised by small and heterogeneous participant samples. Evaluations were generally concerned with cue-exposure craving and urge responses to substances, rather than behavioural change to reduce harmful consumption or preventing drinking. Seven of the studies featured a control condition and only one study did not (Lee et al., 2007). Only one intervention used VR as part of a longitudinal study and reported improvements in screening, testing, and referral skills of healthcare professionals (Fleming et al., 2009). Two studies collected data using a pre- and post-design (Hadley et al., 2014; Lee et al., 2007), while the remaining five studies were crosssectional. As sustained effects over time were generally not measured and behaviour change was not assessed, only limited conclusions can be drawn. While the majority of studies featured a control condition of some kind, these were used to demonstrate the efficacy of study materials, rather than to determine the effect of using VR as an educational tool. Future studies with VR should accommodate a longitudinal controlled trial design in order to demonstrate simulation validity and assess long-term behavioural change. It is also important to compare educational content that is delivered via VR against non-VR alternatives to assess which approach is more effective.

\section{Prevention versus intervention}

The majority of alcohol and VR studies were treatment focussed, rather than focusing on the prevention of alcohol-related problems or reducing drinking behaviour. Only Lee et al. (2007) focussed on using VR with the aim to reduce alcohol craving and urges while others used VR for driving simulations (Arnedt et al., 2001; Meda et al., 2009; Rzepecki-Smith et al., 2009) and training purposes (Fleming et al, 2009). Hadley et al. (2014) included some peer pressure components in their study with virtual peers offering substances and alcohol as well as including prompts to engage in sexual behaviour. However, as the simulation was a set pathway simulation, an acceptance/decline decision-making component was not included, which could have potentially shown how peer pressure impacts risk-behaviour decisions. With peer pressure being a key reason for first time-use of alcohol and drugs (Posthuma, 2013; Andrade et al., 2008) this provides a promising avenue for future VR research. How an individual copes, manages, overcomes, and generally 'bounces back' from adversity or stress is referred to as an individual's resilience (Smith et al., 2008). School based attempts at 
improving resilience in the past have produced mixed results (Pitzer and Skinner, 2016; Lang et al., 2016; Foxcroft and Tsertsvadze, 2011). Previous research has suggested that CET is effective in building resistance towards substances in various at-risk groups (Unrod et al., 2014; Vollstädt-Klein et al., 2011). However, there seems to be little research aiming to understand how resilience skills can be increased using VR and CET in the context of alcohol education. Given VR's effectiveness at eliciting alcohol cravings in CET studies, progressive approaches to educating young people in risk-taking behaviour could benefit from combining resilience building with education on alcohol consumption and related harms in VR simulations.

\section{Research limitations}

A limitation of our study stems from being unable to determine and compare the effect sizes of the alcohol studies due to different study contexts, outcome measures, and reporting quality - a common limitation of systematic literature reviews. Since the heterogeneity of the identified studies did not allow for the production of a meta-analysis, a qualitative description of the studies was conducted. The review's evidence base is limited to recent English language articles published in peer-reviewed journals. Although the authors endeavoured to identify all sources of information about each of the eight studies, including peer-reviewed publications, intervention reports and websites, it should be noted that this analysis was limited to the information provided in those sources.

While eight studies identified for a systematic literature review may appear small there is published evidence in the prevention science literature (Janssen et al., 2013) as well as other disciplines (Price et al., 2017) that feature systematic reviews with a similar number of analysed studies. Novel research contexts (Hindmarsh et al., 2015) and/or subject specific research (Janssen et al., 2013) appear to be the main reasons for the smaller number of identified studies. Due to the novelty of VR research in the context of alcohol studies the authors' suspect that much work in this area is currently in progress, but not yet published. This review excluded grey literature and conference papers, as the authors were strictly concerned with determining the state of peer reviewed research concerning alcohol studies utilising VR technology.

\section{Future research}

Future research should investigate grey literature and conference papers as they may contain additional information on current VR alcohol studies. It is likely that many more research trials will be established to test the application of VR in alcohol studies once the barriers (e.g. costs and accessibility) to utilising VR technology are further reduced (Gaudiosi, 2016; Hall and Betters, 2016; Orland, 2016). As the majority of studies were focussed on problem drinkers, future studies should also explore other vulnerable groups such as non-drinking adolescents. Educating adolescents and young people, at-risk groups and other alcohol drinkers on reduced consumption and quantity control with the goal of preventing alcohol-related harm is an important research agenda (NPHT, 2008). Teaching within virtual environments offers a novel way of delivering more engaging alcohol education, with a variety of advantages to traditional methods. Conventional approaches to delivering behaviour change interventions to young people include didactic classroom-based approaches emphasising skill development and a positive school environment (Roche et al., 2010). While a progressive 'learning by doing' 
approach is an effective method to teaching in schools, it is not normally possible when considering topics such as alcohol, drug and sex education (Tupper, 2008). VR technology enables educators to expose young people to environments of risk-taking (e.g. substance use, sexual risk taking cues, etc.) without the physical danger that these behaviours are associated with in real life. Furthermore, as these environments can be controlled by educators, lessons and consequences can be introduced, in order to satisfy an underlying need to fulfil a specific didactic objective. VR therefore provides potential to further enhance the successful 'learning by doing' approach by complementing existing lesson plans with game design elements. The design of gamification solutions that utilise VR should therefore be explored.

\section{Conclusion}

VR is still in its infancy after having emerged first in the late 1980s, and then disappeared mostly due to the high costs for components at the time. The resurgence of VR over the last years has been exciting for health educators and researchers due to the technologies potential to revolutionise the way we teach and learn. This review showcases that VR's application in alcohol studies remains underutilised. However, it is likely that a number of research trials utilising VR in alcohol studies are currently being developed, implemented and tested. Considering the efficacy of VR reported in the studies within this review and the diminishing barriers to using VR technology, the authors encourage further empirical investigation of VR in alcohol studies to continue growing the evidence base for this burgeoning technology. 


\section{References}

Andrade PP, Pérez DLBC, Alfaro ML, Sánchez OM and López MDOA (2008). Resistancee to peer and partner pressure and tobacco and alcohol use among adolescents. Adicciones 21(3): 243-250.

An-Long $\mathrm{H}$ (2013). Research into the application of virtual reality technology in simulation of sports training. Information Technology Journal 12(20): 5689-5692.

Arnedt JT, Wilde GJ, Munt PW and MacLean AW (2001) How do prolonged wakefulness and alcohol compare in the decrements they produce on a simulated driving task? Accident Analysis \& Prevention 33(3): 337-344.

Bakhuys Roozeboom M, Visschedijk G and Oprins E (2015) The effectiveness of three serious games measuring generic learning features. British Journal of Educational Technology 48(1): 83-100.

Bavas J (2015) Alcohol-fuelled violence: Queensland government tight-lipped on delivering election pledge. $A B C$ Premium News, 12 May.

Biocca F and Levy MR (1995) Communication in the Age of Virtual Reality. Lawrence Erlbaum Associates.

Blom K and Beckhaus S (2013) Virtual travel collisions: Response method influences perceived realism of virtual environments. ACM Transactions on Applied Perception (TAP) 10(4): 1-19.

Boas YAGV (2013) Overview of Virtual Reality Technologies. In: Proceedings of the Interactive Multimedia Conference. University of Southhampton, UK, 8 January 2013, no page range provided.

Bordnick PS, Traylor A, Copp HL, Graap KM, Carter B, Ferrer M and Walton AP (2008) Assessing reactivity to virtual reality alcohol based cues. Addictive Behaviors 33(6): 743-756.

Cooney NL, Litt MD, Cooney JL, Pilkey DT, Steinburg HR and Oncken CA (2007) Alcohol and Tobacco Cessation in Alcohol-Dependent Smokers: Analysis of Real-Time Reports. Psychology of Addictive Behaviors 21(3): 277-286.

Cruz-Neira C, Sandin DJ and DeFanti TA (1993) Surround-screen projection-based virtual reality: the design and implementation of the CAVE. In: Proceedings of the 20th annual conference on Computer graphics and interactive techniques (ed MC Whitten), Anaheim, CA 2-6 August, pp. 135-142. New York: ACM.

Dietrich T, Trischler J, Schuster L and Rundle-Thiele S (2017) Co-designing services with vulnerable consumers. Journal of Service Theory and Practice 27(3): 663-688.

Deterding S, Sicart M, Nacke L, O'Hara K and Dixon D (2011) Gamification. using game-design elements in non-gaming contexts. In: $\mathrm{CHI}$ '11 Extended Abstracts on Human Factors in Computing Systems (eds D Tan, B Begole and WA Kellogg) Vancouver, BC, Canada, 7-12 May 2011. pp. 2425-2428. New York: ACM.

De Visser R, Graber R, Hart A, Abraham C, Scanlon T, Watten P and Memon A (2015). Using qualitative methods within a mixed-methods approach to developing and evaluating interventions to address harmful alcohol use among young people. Health Psychology 34(4): 349-360.

Fleming M, Olsen D, Stathes H, Boteler L, Grossberg P, Pfeifer J, Schiro S, Banning J and Skochelak S (2009) Virtual reality skills training for health care professionals in alcohol screening and brief intervention. The Journal of the American Board of Family Medicine 22(4): 387-398.

Foxcroft DR and Tsertsvadze A (2011) Universal school-based prevention programs for alcohol misuse in young people. The Cochrane Database of Systematic Reviews, (9): 450-575. 
Gaudiosi J (2016) Over 200 Million VR Headsets to be sold by 2020. Fortune, 21 January.

Hadley W, Houck CD, Barker DH, Garcia AM, Spitalnick JS, Curtis V, Roye S and Brown LK (2014). Eliciting affect via immersive virtual reality: A tool for adolescent risk reduction. Journal of Pediatric Psychology 39(3): 358-368.

Hall C and Betters E (2016). Best headsets to buy in 2016, whatever your budget. Pocket-lint, 20 January.

Hanson K and Shelton BE (2008) Design and Development of Virtual Reality: Analysis of Challenges Faced by Educators. Educational Technology \& Society 11(1): 118-131.

Hindmarsh CS, Jones SC and Kervin L (2015) Effectiveness of alcohol media literacy programmes: a systematic literature review. Health Education Research 30(3): 449-465.

Janssen MM, Mathijssen JJ, Van Bon-Martens MJ, Van Oers HA and Garretsen HF (2013) Effectiveness of alcohol prevention interventions based on the principles of social marketing: a systematic review. Substance Abuse Treatment, Prevention, and Policy 8(18): 1-11.

Jernigan DH and Babor TF (2015) The concentration of the global alcohol industry and its penetration in the African region: Alcohol industry penetration in Africa. Addiction 110(4): 551-560.

Johnson D, Deterding S, Kuhn KA, Staneva A, Stoyanov S and Hides L (2016) Gamification for health and wellbeing: A systematic review of the literature. Internet Interventions 6: 89106.

Kim CM, Youn JH, Ji YK and Choi DY (2014) Design and assessment of a virtual underwater multisensory effects reproducing simulation system. International Journal of Distributed Sensor Networks 10(7): pp. 420-428.

Krueger MW (1991) Artificial Reality II. USA: Addison-Wesley Professional.

Kubacki K, Rundle-Thiele S, Pang B and Buyucek N (2015) Minimizing alcohol harm: A systematic social marketing review (2000-2014). Journal of Business Research 68(10): 2214-2222.

Kuo RL, Delvecchio FC and Preminger GM (2001) Virtual reality: Current urologic applications and future developments. Journal of Endourology 15(1): 117-122.

Lang C, Feldmeth AK, Brand S, Holsboer-Trachsler E, Pühse U and Gerber M (2016) Effects of a physical education-based coping training on adolescents' coping skills, stress perceptions and quality of sleep. Physical Education and Sport Pedagogy 1(18): 213230.

Laramee RS and Ware C (2002) Rivalry and interference with a head-mounted display. ACM Transactions on Computer-Human Interaction 9(3): 238-251.

Lee JH, Kwon H, Choi J and Yang BH (2007) Cue-exposure therapy to decrease alcohol craving in virtual environment. CyberPsychology \& Behavior 10(5): 617-623.

Liberati A, Altman DG, Tetzlaff J, Mulroow C, Gøtzsche PC, Loannidis JPA, Clarke M, Devereaux PJ, Kleijnen J and Moher D (2009) The PRISMA statement for reporting systematic reviews and meta-analyses of studies that evaluate health care interventions: Explanation and elaboration. PLoS Medicine 6(7).

Mayor S (2011) Government says no to lowering drink driving limit in UK. BMJ (Clinical Research Ed.) 342: d1877.

Meda SA, Calhoun VD, Astur RS, Turner BM, Ruopp K and Perlson GD (2009) Alcohol dose effects on brain circuits during simulated driving: An fMRI study. Human Brain Mapping 30(4): 1257-1270. 
Moher D, Liberati A, Tetzlaff J and Altman DG (2009) Preferred reporting items for systematic reviews and meta-analyses: The PRISMA statement. PLoS Medicine 151(4).

Olszewski K, Lim JJ, Saito S and Li H (2016) High-fidelity facial and speech animation for VR HMDs. ACM Transactions on Graphics (TOG) 35(6): 1-14.

Orland K (2016) Oculus founder: "your crappy PC is the biggest barrier to [VR] adoption". arsTECHNICA, 13 January.

Pitzer J and Skinner E (2016) Predictors of changes in students' motivational resilience over the school year: The roles of teacher support, self-appraisals, and emotional reactivity. International Journal of Behavioral Development 41(1): 15-29.

Posthuma JL (2013) Adolescent susceptibility to differing types of peer influences on alcohol and marijuana use. PhD thesis, Alliant International University, USA.

Price C, Cohen D, Pribis P and Cerami J (2017). Nutrition Education and Body Mass Index in Grades K-12: A Systematic Review. Journal of School Health 87(9): 715-720.

Robison RA, Liu CY and Apuzzo ML (2011) Man, mind, and machine: The past and future of virtual reality simulation in neurologic surgery. World Neurosurgery 76(5): 419-430.

Roche A, Bywood P Hughes C, Freeman T, Duraisingam V, Trifonoff A, Tovell A and Steenson T (2010). Reducing alcohol-related health inequities: An evidence summary. Report, Commonwealth of Australia: National Centre for Education and Training on Addiction, Australia, September.

Rundle-Thiele S, Schuster L, Dietrich T, Russell-Bennett R, Drennan J, Leo C and Connor JP (2015) Maintaining or changing a drinking behavior? GOKA's short-term outcomes. Journal of Business Research 68(10): 2155-2163.

Rzepecki-Smith Cl, Meda SA, Calhoun VD, Stevens MC, Jafri MJ, Astur RS and Pearlson GD (2010) Disruptions in functional network connectivity during alcohol intoxicated driving. Alcoholism Clinical and Experimental Research 34(3): 479-487.

Sárkány A, Tősér Z, Verő AL, Lőrincz A, Toyama T, Toosi EN \& Sonntag D (2015) Maintain and Improve Mental Health by Smart Virtual Reality Serious Games. In: Pervasive Computing Paradigms for Mental Health. (eds S Serino, A Matic, D Giakoumis, G Lopez and P Cipresso), Milan, Italy, 24-25 September 2015, pp. 12-14. Springer International Publishing.

Scott K (2015). Australia's binge drinking culture puts mental health at risk, experts warn. $A B C$ News, 30 March.

Slater M, Lotto B, Arnold MM and Sanchez-Vives MV (2009) How we experience immersive virtual environments: the concept of presence and its measurement. The UB Journal of psychology 40(2): 193-210.

Smith BW, Dalen J, Wiggins K, Tooley E, Christopher P and Bernard J (2008) The brief resilience scale: Assessing the ability to bounce back. International Journal of Behavioural Medicine 15(3): 194-200.

Terer K and Brown R (2014) Effective drink driving prevention and enforcement strategies: Approaches to improving practice. Trends \& issues in crime and criminal justice. 471: 461-480.

Traylor AC, Parrish DE, Copp HL and Bordnick PS (2011) Using virtual reality to investigate complex and contextual cue reactivity in nicotine dependent problem drinkers. Addictive Behaviors 36(11): 1068-1075.

Tupper KW (2008) Teaching teachers to just say "know": Reflections on drug education. Teaching and Teacher Education 24(2): 356-367. 
Unrod M, Drobes DH, Stasiewicz PR, Ditre JW, Heckman B, Miller RR, Sutton SK and Brandon TH (2014) Decline in cue-provoked craving during cue exposure therapy for smoking cessation. Nicotine \& Tobacco Research: Official Journal of the Society for Research on Nicotine and Tobacco 16(3): 306-315.

Vollstädt-Klein S, Loeber S, Kircsh M, Bach P, Richter A, Bühler M, Von Der Goltz C, Hermann $D$, Mann $K$ and Kiefer $F$ (2011) Effects of cue-exposure treatment on neural cue reactivity in alcohol dependence: A randomized trial. Biological Psychiatry 69(11): 10601066.

World Health Organisation (2014) Global status report on alcohol and health. World Health Organisation. Available at: http://www.who.int/substance abuse/publications/global alcohol report/msb gsr 2 014 1.pdf?ua=1.

Zyda M (2005) From visual simulation to virtual reality to games. Computer 38(9): 25-32. 
Figure 1 - Flowchart

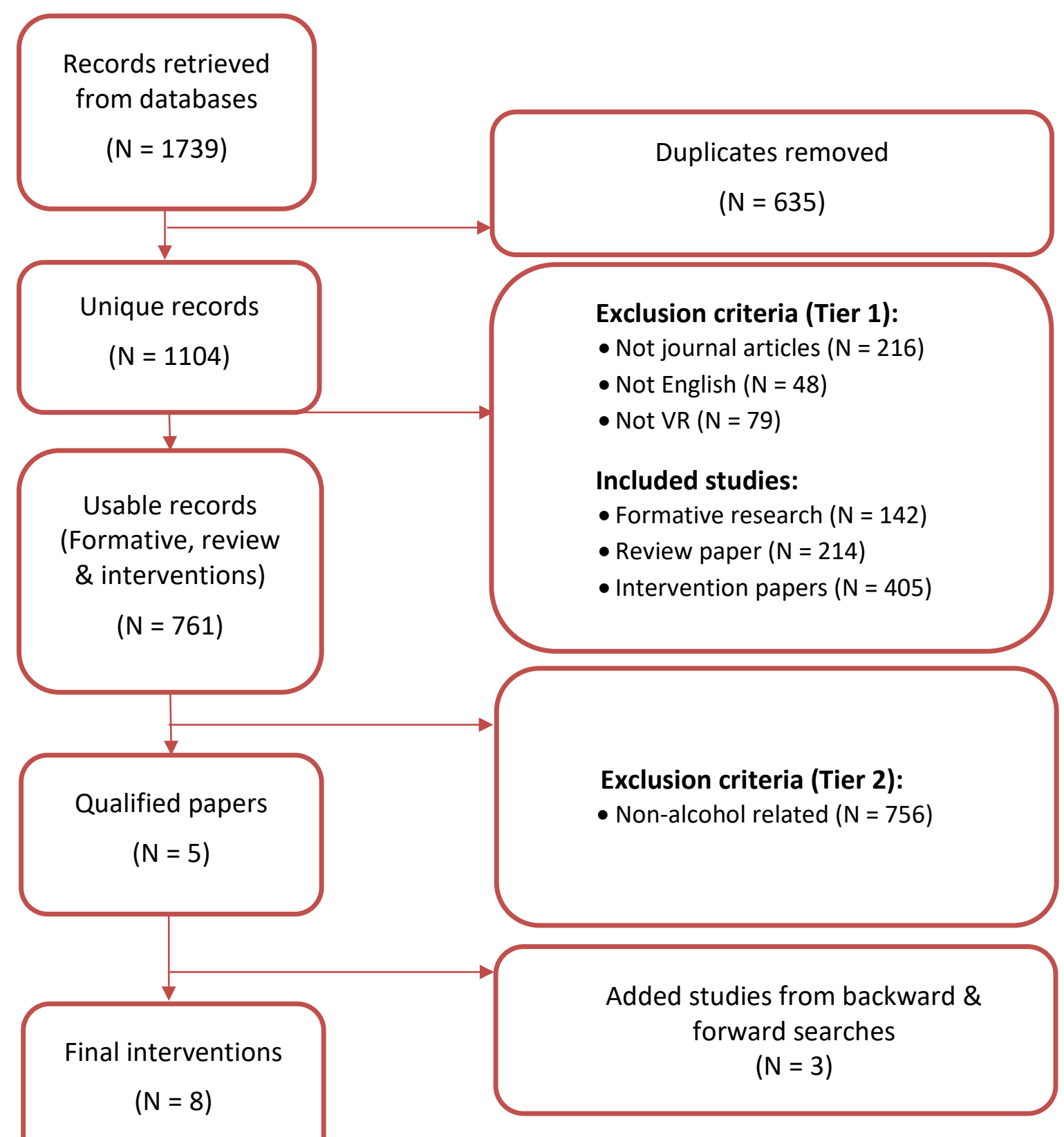


Table 1 - Study Characteristics

\begin{tabular}{|c|c|c|c|c|c|c|c|}
\hline Author & $\begin{array}{l}\text { Country } \\
\text { of origin }\end{array}$ & Sample & Target audience & $\begin{array}{c}\text { User involvement in } \\
\text { design }\end{array}$ & Objectives & Study design & VR technology \\
\hline $\begin{array}{l}\text { Arnedt et al., } 2001 \text { - “How do Prolonged } \\
\text { Wakefulness and Alcohol Compare in the } \\
\text { Decrements they Produce on a Simulated } \\
\text { Driving Task?” }\end{array}$ & Canada & $\mathrm{N}=18$ & $\begin{array}{l}\text { Adult license holding male } \\
\text { drinkers }\end{array}$ & Not reported & $\begin{array}{l}\text { Examined the performance of a } \\
\text { driving VR simulator, and } \\
\text { impairments produced by raising } \\
\text { BAC's* and sleepiness. }\end{array}$ & $\begin{array}{l}\text { Cross-sectional experimental research with } \\
\text { control BAC }{ }^{*} \text { condition. }\end{array}$ & $\begin{array}{l}\text { Interactive } \\
\text { computer } \\
\text { programme }\end{array}$ \\
\hline $\begin{array}{l}\text { Lee et al., } 2007 \text { - "Cue-Exposure } \\
\text { Therapy to Decrease Alcohol Craving in } \\
\text { Virtual Environments" }\end{array}$ & $\begin{array}{l}\text { South } \\
\text { Korea }\end{array}$ & $\mathrm{N}=8$ & $\begin{array}{l}\text { Alcohol dependent and } \\
\text { recovering alcoholics }\end{array}$ & $\begin{array}{l}\text { Participants provided } \\
\text { alcohol preferences for } \\
\text { the VR narrative }\end{array}$ & $\begin{array}{l}\text { To investigate whether CET }{ }^{+} \text {using } \\
\text { VR was an effective method of } \\
\text { reducing alcohol craving in alcohol } \\
\text { dependent subjects. }\end{array}$ & $\begin{array}{l}\text { Pre-post assessment with non-control } \\
\text { experimental design. Data acquired through } \\
\text { self-administered questionnaires at the end } \\
\text { of each session. }\end{array}$ & $\begin{array}{l}\text { Interactive } \\
\text { computer } \\
\text { programme }\end{array}$ \\
\hline $\begin{array}{l}\text { Bordnick et al., } 2008 \text { - “Assessing } \\
\text { Reactivity to Virtual Reality Alcohol } \\
\text { Based Cues” }\end{array}$ & USA & $\mathrm{N}=82$ & $\begin{array}{l}\text { Middle aged U.S citizens with } \\
\text { alcohol use disorders not } \\
\text { seeking treatment }\end{array}$ & Not reported & $\begin{array}{l}\text { To develop a system for VR } \\
\text { ACRAS*. }\end{array}$ & $\begin{array}{l}\text { Cross-sectional, controlled study. Baseline } \\
\text { familiarity and standardisation performed. }\end{array}$ & $\mathrm{HMD}^{* * * *}$ \\
\hline $\begin{array}{l}\text { Fleming et al., } 2009 \text { - "Virtual Reality } \\
\text { Skills Training for Health Care } \\
\text { Professionals in Alcohol Screening and } \\
\text { Brief Intervention” }\end{array}$ & USA & $\mathrm{N}=102$ & $\begin{array}{l}\text { Physicians/ } \\
\text { Healthcare professionals }\end{array}$ & Not reported & $\begin{array}{l}\text { Developed and tested a self- } \\
\text { contained VR simulation with the } \\
\text { aim to improve clinical skills of } \\
\text { health professionals. }\end{array}$ & $\begin{array}{l}\text { Six month longitudinal randomised } \\
\text { controlled trial intervention conducted over } \\
10 \text { sessions in six weeks for baseline tests } \\
\text { with six month follow-up. }\end{array}$ & $\begin{array}{l}\text { Interactive } \\
\text { computer } \\
\text { programme }\end{array}$ \\
\hline $\begin{array}{l}\text { Meda et al., } 2009 \text { - "Alcohol Dose } \\
\text { Effects on Brain Circuits during } \\
\text { Simulated Driving: an fMRI }{ }^{\&} \text { study" }\end{array}$ & USA & $\mathrm{N}=40$ & $\begin{array}{l}\text { License holding adults who } \\
\text { frequently drink drive }\end{array}$ & Not reported & $\begin{array}{l}\text { Identify alcohol dose-related } \\
\text { disruptions, individual behavioural } \\
\text { and associated neural network } \\
\text { changes while driving under the } \\
\text { influence. }\end{array}$ & $\begin{array}{l}\text { Cross-sectional blinded randomised } \\
\text { controlled trial. Performance scored after } \\
\text { each participant session. }\end{array}$ & $\begin{array}{l}\text { Interactive } \\
\text { computer } \\
\text { programme }\end{array}$ \\
\hline $\begin{array}{l}\text { Rzepecki-Smith et al., } 2009 \text { - } \\
\text { "Disruptions in Functional Network } \\
\text { Connectivity During Alcohol Intoxicated } \\
\text { Driving” }\end{array}$ & USA & $\mathrm{N}=40$ & $\begin{array}{l}\text { License holding adults who } \\
\text { frequently drink drive }\end{array}$ & Not reported & $\begin{array}{l}\text { Explore connections and } \\
\text { communications in brain circuits } \\
\text { when sober and intoxicated. }\end{array}$ & $\begin{array}{l}\text { Cross-sectional blind randomised } \\
\text { controlled trial. Performance scored after } \\
\text { each participant session. }\end{array}$ & $\begin{array}{l}\text { Interactive } \\
\text { computer } \\
\text { programme }\end{array}$ \\
\hline $\begin{array}{l}\text { Traylor et al., } 2011 \text { - “Using Virtual } \\
\text { Reality to Investigate Complex and } \\
\text { Contextual Cue Reactivity in Nicotine } \\
\text { Dependent Problem Drinkers” }\end{array}$ & USA & $\mathrm{N}=21$ & $\begin{array}{l}\text { Nicotine dependent problem } \\
\text { drinking adults }\end{array}$ & Not reported & $\begin{array}{l}\text { To explore and compare effects in } \\
\text { cross-cue reactivity and assess the } \\
\text { effectiveness of VR in CET }\end{array}$ & $\begin{array}{l}\text { Cross-sectional, control random sampling. } \\
\text { Repeated measures MANOVAS and post- } \\
\text { hoc independent t-tests. }\end{array}$ & $\mathrm{HMD}^{* * * *}$ \\
\hline $\begin{array}{l}\text { Hadley et al., } 2014 \text { - “Eliciting Affect via } \\
\text { Immersive Virtual Reality: A Tool for } \\
\text { Adolescent Risk Reduction” }\end{array}$ & USA & $\mathrm{N}=42$ & $\begin{array}{l}\text { Adolescents exposed to alcohol } \\
\text { and sexual risks }\end{array}$ & $\begin{array}{l}\text { Iterative story } \\
\text { formulation - Informants }\end{array}$ & $\begin{array}{l}\text { To design and test efficacy of a VR } \\
\text { House party in arousal responses to } \\
\text { positively influence affect } \\
\text { management in adolescents. }\end{array}$ & $\begin{array}{l}\text { Pre and post-test design, with data recorded } \\
\text { at baseline (neutral room), during } \\
\text { experiment (virtual house party) and post- } \\
\text { experiment (return to neutral room) stages. }\end{array}$ & $\mathrm{HMD}^{* * * *}$ \\
\hline
\end{tabular}

${ }^{*}$ Blood alcohol concentration, ${ }^{* *}$ Alcohol cue reactivity assessment ${ }^{* * *}$ Head Mounted Display, ${ }^{+}$Cue-exposure therapy, ${ }^{\text {\&Functional magnetic resonance imager }}$ 
Table 2 - Summary of Study Measures, Results and Limitations

\begin{tabular}{|c|c|c|c|c|}
\hline Author & Measures & Description & Results & Limitations \\
\hline Arnedt et al., 2001 & $\begin{array}{l}\text { SSS* used to rate current } \\
\text { tiredness. }\end{array}$ & $\begin{array}{l}\text { Driving simulation with } \\
\text { three different BAC }{ }^{\&} \text { levels } \\
(0.00,0.05 \text { and } 0.08) \text {. }\end{array}$ & $\begin{array}{l}\text { Sleepiness ratings increased alongside alcohol dosage for SSS*. As } \\
\text { dosage increased, so did tracking variability, speed variability and the } \\
\text { number of off-road incidents. Alcohol produced a more marked increase } \\
\text { in speed than prolonged wakefulness. }\end{array}$ & $\begin{array}{l}\text { Time of day effects were absent for all measures. Generalisations made comparing } \\
\text { prolonged wakefulness and alcohol must consider that the measures were limited } \\
\text { to speed and road position and drivers were not exposed to other traffic or complex } \\
\text { decision making. }\end{array}$ \\
\hline Lee et al., 2007 & $\begin{array}{l}\text { Penn Alcohol Craving Scale, the } \\
\text { Alcohol Urge Questionnaire and } \\
\text { Obsessive Compulsive Drinking } \\
\text { Scale. }\end{array}$ & $\begin{array}{l}\text { Alcoholics' Anonymous } \\
\text { members placed in two } \\
\text { VE's*; for eight sessions. } \\
\text { Responses to cues/contexts } \\
\text { recorded. }\end{array}$ & $\begin{array}{l}\text { A reduction in cue-elicited craving after VR CET }{ }^{* * *} \text { was reported. } \\
\text { Alcohol urges decreased after the final session, but were not significant. }\end{array}$ & $\begin{array}{l}\text { Treatment effect to decrease craving ambiguous when comparing pre-and } \\
\text { posttreatment. Two participants were abstinent from alcohol for approx. } 13 \text { years, } \\
\text { potentially causing insignificant results. Sample size was low and generalisability } \\
\text { of results is limited. Two VR scenarios may be insufficient to cover all familiar } \\
\text { conditioned responses. Self-reports may not predict relapse well. }\end{array}$ \\
\hline $\begin{array}{l}\text { Bordnick et al., } \\
2008\end{array}$ & $\begin{array}{l}\text { DSM-IV-TR interview model } \\
\text { VAS scale measured attention to } \\
\text { cues. Presence Questionnaire of } \\
24 \text { items with a 7-point Likert } \\
\text { scale. }\end{array}$ & $\begin{array}{l}\text { Personalised CET }{ }^{* * *} \text { paths, } \\
\text { participants given control } \\
\text { over responses to cues. }\end{array}$ & $\begin{array}{l}\text { A significant effect of VR rooms for subjective craving was found. } \\
\text { Ratings in the argument room were significantly lower compared other } \\
\text { rooms. Significant effects for VR rooms were found on sight, smell, and } \\
\text { thought items. Scores were greater in the bar, kitchen, party and } \\
\text { argument rooms compared to the neutral (gallery) room. }\end{array}$ & $\begin{array}{l}\text { Single item craving ratings are limited by reliability and validity concerns. } \\
\text { Participants may have been under the influence of other drugs that weren't } \\
\text { reported in the interview, which potentially effected craving and other results. The } \\
\text { sample consisted of alcohol abusing or dependent non-treatment-seeking drinkers. }\end{array}$ \\
\hline $\begin{array}{l}\text { Fleming et al., } \\
2009\end{array}$ & $\begin{array}{l}\text { Measured } 17 \text { skills on a 5-point } \\
\text { Likert-scale. }\end{array}$ & $\begin{array}{l}\text { Six training scenarios for } \\
\text { screening, testing, and } \\
\text { referral. }\end{array}$ & $\begin{array}{l}\text { Significant differences were detected between groups for alcohol } \\
\text { screening (minor in control, larger in interventions) and brief } \\
\text { intervention skills (improvement for intervention, decline in control). }\end{array}$ & $\begin{array}{l}\text { Scoring remained a challenge despite pilot testing. Ceiling effect caused by a } \\
\text { sample of interested volunteers hindering generalisability. The use of an interactive } \\
\text { computer programme over HMD's }{ }^{+} \text {may have hindered immersion and therefore } \\
\text { outcome effects. }\end{array}$ \\
\hline Meda et al., 2009 & $\begin{array}{l}14 \text { total driving related } \\
\text { components. }\end{array}$ & $\begin{array}{l}\text { Participants placed in a } \\
\text { driving simulator with no } \\
(0.0 \%) \text {, moderate }(0.05 \%) \text {, } \\
\text { or high }(0.10 \%) \text { BAC }^{\&} \text {. }\end{array}$ & $\begin{array}{l}\text { A main effect analysis of behavioural data across alcohol dosage } \\
\text { revealed that opposite white line crossings and mean speed were } \\
\text { significantly different and demonstrated a dose-related linear response. }\end{array}$ & $\begin{array}{l}\text { Study design prevented the researchers from conducting and analysing the data on } \\
\text { a finer temporal scale. The general linear model analysis was not sensitive enough. }\end{array}$ \\
\hline $\begin{array}{l}\text { Rzepecki-Smith et } \\
\text { al., } 2009\end{array}$ & $\begin{array}{l}\text { Data on driving performance and } \\
\text { neural function. }\end{array}$ & $\begin{array}{l}\text { Participants were placed in a } \\
\text { driving simulator with high } \\
\text { levels of } \operatorname{BAC}^{\&}(0.10 \%) \text {. }\end{array}$ & $\begin{array}{l}\text { Specific disruptions of functional network connectivity between the } \\
\text { frontal-temporal-basal ganglia and the cerebellar circuits were found at } \\
\text { active dose. Change scores of correlations between the frontal-temporal- } \\
\text { basal ganglia and cerebellar circuits were significantly associated with } \\
\text { unstable motor vehicle steering. }\end{array}$ & $\begin{array}{l}\text { The ICA^ and FNC }{ }^{\wedge} \text { approach used in the study is restricted to five driving- } \\
\text { associated alcohol-influenced circuits. Participants in the study were all moderate- } \\
\text { social drinkers. }\end{array}$ \\
\hline Traylor et al., 2011 & $\begin{array}{l}\text { Mini International } \\
\text { Neuropsychiatric Interview, } \\
\text { Nicotine Dependence } \\
\text { Questionnaire and Alcohol } \\
\text { Dependence Scale. }\end{array}$ & $\begin{array}{l}\text { Participants were } \\
\text { randomised into one of two } \\
\text { path scenarios through a } \\
\text { virtual environment. }\end{array}$ & $\begin{array}{l}\text { The alcohol dependent group reported significantly higher alcohol } \\
\text { cravings in the office scenario and the neutral scene compared to the } \\
\text { non-alcohol dependent group. A within-subjects effect of VR context on } \\
\text { alcohol craving was found. }\end{array}$ & $\begin{array}{l}\text { The characteristics of the sample participants may differ to other populations } \\
\text { of nicotine dependent problem drinkers. People with significant physical/mental } \\
\text { health issues were disqualified. The alcohol abstinence period may also have led to } \\
\text { increased background craving. }\end{array}$ \\
\hline Hadley et al., 2014 & SSA scale $\$$. & $\begin{array}{l}\text { Participants led through } \\
\text { IVR }{ }^{@} \text { party scenarios. } \\
\text { Participants offered } \\
\text { substances by virtual } \\
\text { characters. }\end{array}$ & $\begin{array}{l}\text { Adolescents reported significant decrease in somatic symptoms from } \\
\text { baseline to post-experiment. Significant increase in Heart Rate and } \\
\text { decrease in RSA }{ }^{\#} \text { between baseline of neutral virtual room and virtual } \\
\text { house party scenario was reported. }\end{array}$ & $\begin{array}{l}\text { The IVR }{ }^{@} \text { party presented cues in rapid succession that likely didn’t simulate real } \\
\text { experiences. The study didn’t directly measure affective arousal state and did not } \\
\text { provide specific data on affect when exposed to sexual/substance use risk factors. } \\
\text { Lack of control arm hinders generalisability. }\end{array}$ \\
\hline
\end{tabular}

${ }^{*}$ Stanford sleepiness scale, ${ }^{\&}$ Blood alcohol concentration, ${ }^{* *}$ Virtual environments, ${ }^{* * *}$ Cue-exposure therapy, ${ }^{+}$Head mounted display, ${ }^{\wedge}$ Independent component analysis, ${ }^{\sim}$ Functional network

connectivity, \$Sensory state awareness, ${ }^{\circledR}$ Interactive virtual reality, ${ }^{*}$ Respiratory sinus arrhythmia 